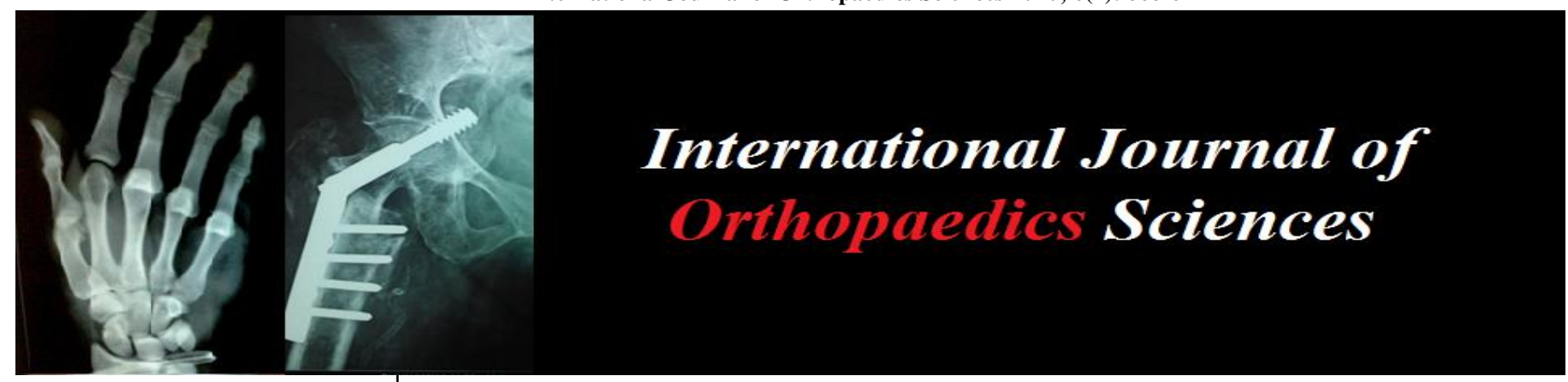

E-ISSN: 2395-1958

P-ISSN: 2706-6630

IJOS 2020; 6(2): 666-671

(C) 2020 IJOS

www.orthopaper.com

Received: 14-02-2020

Accepted: 16-03-2020

Dr. Vimala Ambati

Dept of Neurosurgery Mamta

Medical College Khammam,

Telangana, India

Dr. Kamesh Konchada

Dept of Neurosurgery Mamta

Medical College Khammam,

Telangana, India

Dr. K Jagadeesh Babu

Dept of Neurosurgery Mamta

Medical College Khammam,

Telangana, India

Dr. G. Malleswara rao

Dept of Neurosurgery Mamta

Medical College Khammam,

Telangana, India

Dr. Chaitanya Juluru

Dept of Neurosurgery Mamta

Medical College Khammam,

Telangana, India

Dr. Manbachan singh Bedi

Dept of Neurosurgery Mamta Medical College Khammam,

Telangana, India

Dr. Tanmay B

Dept of Neurosurgery Mamta

Medical College Khammam,

Telangana, India

Dr. Aravind J

Dept of Neurosurgery Mamta

Medical College Khammam,

Telangana, India

Dr. Sai varun J

Dept of Neurosurgery Mamta Medical College Khammam,

Telangana, India

Corresponding Author: Dr. Vimala Ambati

Dept of Neurosurgery Mamta Medical College Khammam,

Telangana, India

\section{Comparative study of open versus endoscopic discectomy (Destandau technique) in lumbar disc herniation at a semi urban set-up}

Dr. Vimala Ambati, Dr. Kamesh Konchada, Dr. K Jagadeesh Babu, Dr. G. Malleswara rao, Dr. Chaitanya Juluru, Dr. Manbachan singh Bedi, Dr. Tanmay B, Dr. Aravind J and Dr. Sai varun J

DOI: https://doi.org/10.22271/ortho.2020.v6.i2k.2116

\section{Abstract}

Study Design: Prospective study.

Aims and objectives: To study the efficacy, advantages, and associated complications of Endoscopic Destandau method in comparison with standard open discectomies in lumbar disc herniations at a semi urban setup.

Materials and methods: A total of 42 patients were enrolled in the study. All the details pertaining to the history, clinical examination, surgical procedure and postoperative recovery were noted. 19 patients underwent discectomy by Endoscopic discectomy by Destandau method (EDM) and 23 patients underwent standard open discectomy (SOD). Patients were followed up for a minimum of 12 months prospectively. Visual analogue score (VAS) was noted preoperatively, immediate postop (48hrs postsurgery) and at follow up. Outcome is measured at 12 months follow up.

Results: $47.6 \%$ patients were in the age group of 31-40 years, most common site to be involved in disc prolapse was L4-L5 in $54.75 \%$. The mean operative time was 82 min and the mean hospital stay was 2.8 days in EDM group compared to 126 mins and 8.5 days of SOD group. Average blood loss is $30 \mathrm{ml}$ in EDM group and $180 \mathrm{ml}$ in SOD group. The outcome was excellent good fair and poor in $47.82 \%$, $43.47 \%, 4.3 \%$ and $4.3 \%$ respectively in SOD group compared to $68.4 \%, 21 \%, 5.3 \%$ and $5.3 \%$ in EDM group.

Conclusions: EDM is novel, safe and effective technique that minimizes invasiveness of surgical approach for lumbar discectomy. The technique also offers decreased blood loss, shorter operative time, shorter in-hospital stay, less immediate postoperative pain, better cosmoses and early recovery to work.

Keywords: Lumbar disc prolapse, discectomy, endospine, destandau, endoscopic discectomy

\section{Introduction}

80 of 100 people will have low back ache at least once in life. ${ }^{[1]}$ Most common site of Lumbar herniation is at L4-L5 followed by L5-S1. Typically, it is presented by low backache and Sciatic pain. Sometimes patients can present with numbness and weakness of his leg in the same territory than radicular pain. The initial management usually consists of rest, analgesic and anti-inflammatory drugs, back strengthening exercises and may be epidural injection and percutaneous nerve root block (only provide temporary benefit, however does not change rate of surgical intervention and long-term functional output) ${ }^{[2]}$. In a study conducted by weber $e t$ al. $70 \%$ of patients responded to conservative management within 4 weeks. ${ }^{[3]}$ An emergency surgery is performed in case of neurologic deficits, saddle anaesthesia, and bowel or bladder dysfunction (cauda equina syndrome). Usually, the symptoms are resolved within six weeks. After this period, the surgery will be proposed if the symptoms (pain and neurological deficits) are persistent. Conventional surgery consists of laminectomy followed by discectomy by posterior approach (standard open discectomy). Several minimally invasive and endoscopic techniques have been proposed and being increasingly used in last 15 years. These include interlaminar, transforaminal, posterolateral, and trans-iliac procedures ${ }^{[4]}$. Endoscopic Destandau's method (EDM) proposed since 1993 is a suitable alternative to standard open discectomy (SOD) ${ }^{[5,6]}$. 
In this study, we present our experience and outcomes of patients operated by this technique, and we compared our results to standard open discectomy surgery at a semi urban set-up.

\section{Material and methods}

A prospective study done at a semi-urban setup in dept of Neurosurgery, Mamata medical college Khammam from November 2018 to July 2019. A total of 42 patient were enrolled in the study. All the details pertaining to the history, clinical examination, surgical procedure, postoperative recovery was noted. 19 patients underwent EDM and 23 patients underwent SOD. Visual analogue score (VAS) was noted preoperatively, immediate postop and at follow up. Patients are followed up for a minimum of 12 months postoperatively.

The surgery was done under general anaesthesia. Patients who underwent Standard open discectomy (SOD) have been operated in prone position under General anaesthesia. Patient who underwent Endoscopic Destandau method the position was Knee-chest in 8 patients and prone in 11 patients. After marking the suitable level with the help of marker tool and carm. A skin incision was made para-median $(5 \mathrm{~mm}$ lateral to spinous processes). Paraspinal muscles are dissected with chisel and pushed laterally. Haemostasis achieved by bipolar cautery. A cotton patty placed at cranial and caudal aspects of the incision. The DESTANDAU-ENDOSPINE system was inserted and placed against the lamina. A hemilaminectomy of superior vertebra was done, the opening of the lamina provides access to the spinal canal. ligamentum flavum was removed with the help of Kerrison upcuts. Dural sac was exposed along with nerve root, both are retracted medially to locate the disc space. Posterior longitudinal ligament was cut and discectomy carried out. The Herniated disc was identified and remove with pituitary forceps. Haemostasis was achieved and wound closed in 2 layers after instilling methylprednisolone over root and infiltrating muscle with buprenorphine. Skin was closed with rapid vicryl.

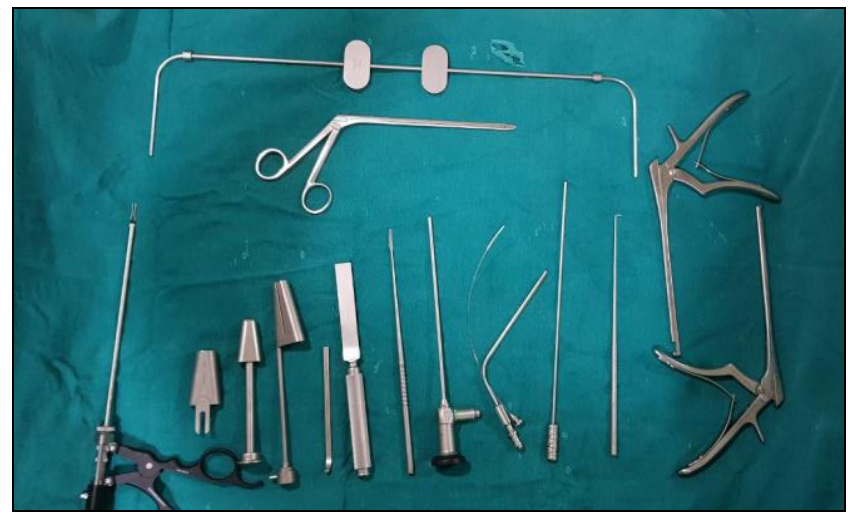

Fig 1: showing the instruments used in Endoscopic discectomy by Destandau method

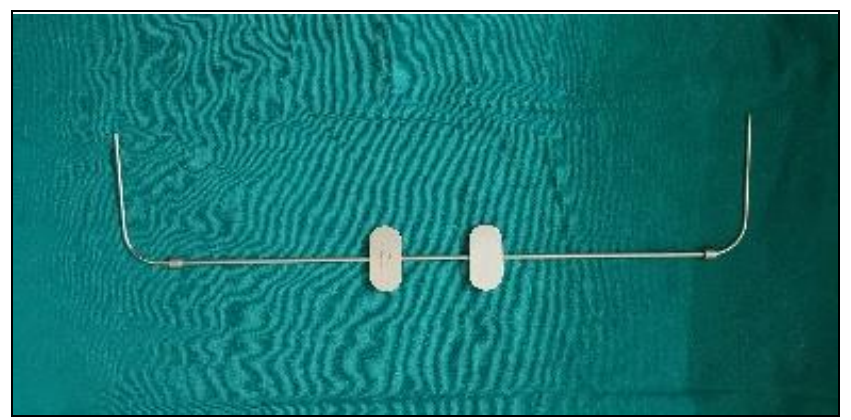

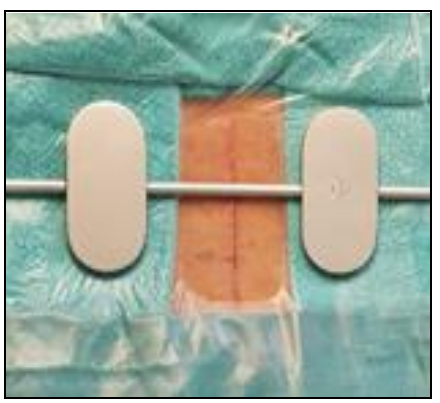

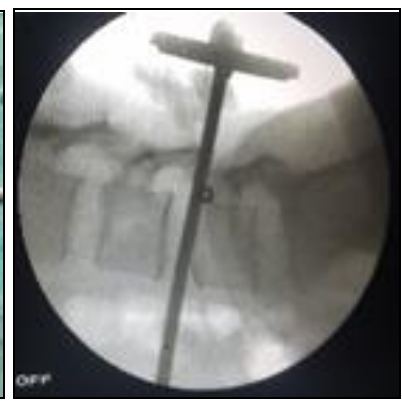

Fig 2: Showing localizer tool and identification of L4-L5 space
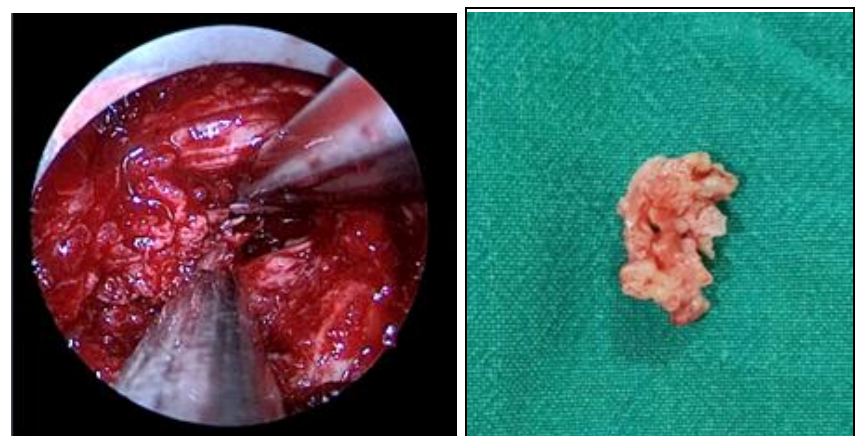

Fig 3,4: showing intra-operative discectomy by Destandau technique and the discectomy specimen
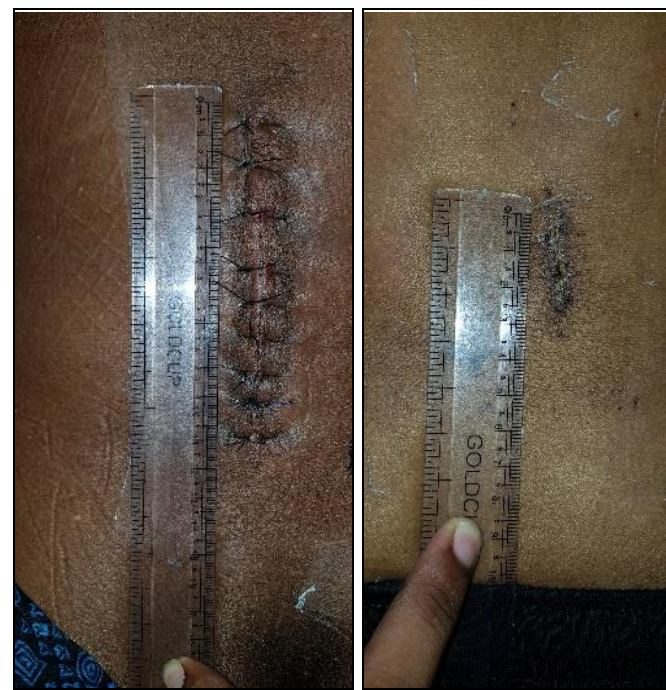

Fig 4: showing comparison of scars of open and endoscopic discectomy

\section{Results}

A total of 42 patients were enrolled in this study. 17 patients were males and 25 patients were females. Most patients (20) were in the age group of 31-40 years and 12 patients were in 41-50yrs, 9 patients in the age group 51-60yrs and one patient in 61-70yrs. 23 patients had disc prolapsed at L4-L5 level followed by 17 patients at L3-L4 level, 2 patients at L5-S1. The mean operative time was $82 \mathrm{~min}$ and the mean hospital stay was 2.8 days in EDM group compared to 126 mins and 8.5 days of SOD group. Average blood loss is $30 \mathrm{ml}$ in EDM group and $180 \mathrm{ml}$ in SOD group. One patient had dural tear in EDM group which was managed with muscle patch plugged into the defect. One patient in EDM group developed traction neuritis which improved with conservative treatment. In one patient of EDM group endoscopic discectomy was converted to open in view of torrential epidural bleeding (it had occurred in the $3^{\text {rd }}$ case, early phase of the learning curve). Mean time taken to return to work was less in EDM group (21 days) compared to 93 days in SOD group. Mean preoperative VAS score was 8.7 and the mean postoperative VAS scores at 
postoperative day 7 and at 6 months were 2.25 and 1.12, respectively in EDM group. 1 patient had surgical site infection in OD group. $47.82 \%, 43.47 \%, 4.3 \%, 4.3 \%$ had excellent, good, fair and poor outcomes in SOD group.
$68.4 \%, 21 \%, 5.3 \%, 5.3 \%$ had excellent, good, fair and poor outcomes in EDM group according to modified Macnab criteria.

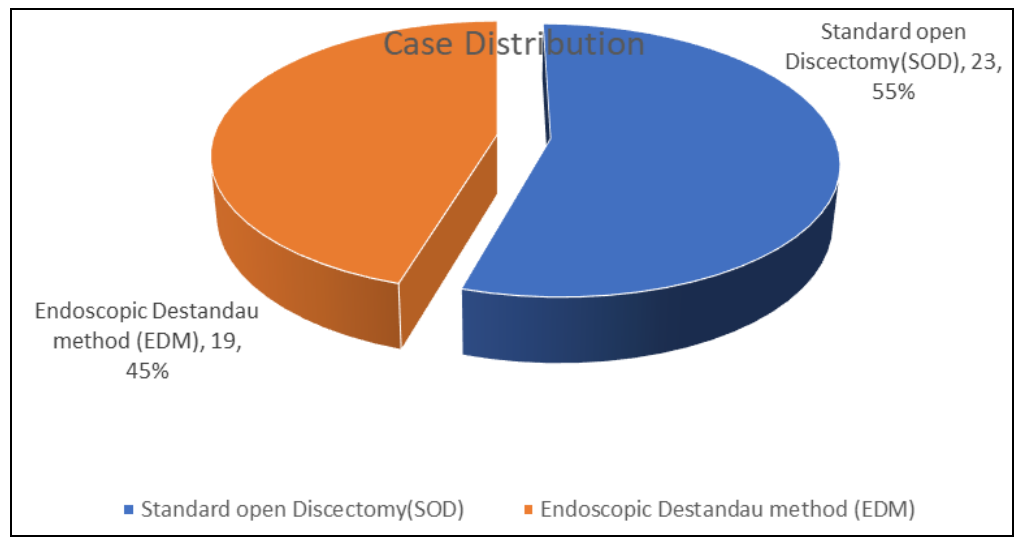

Fig 6: Case Distribution

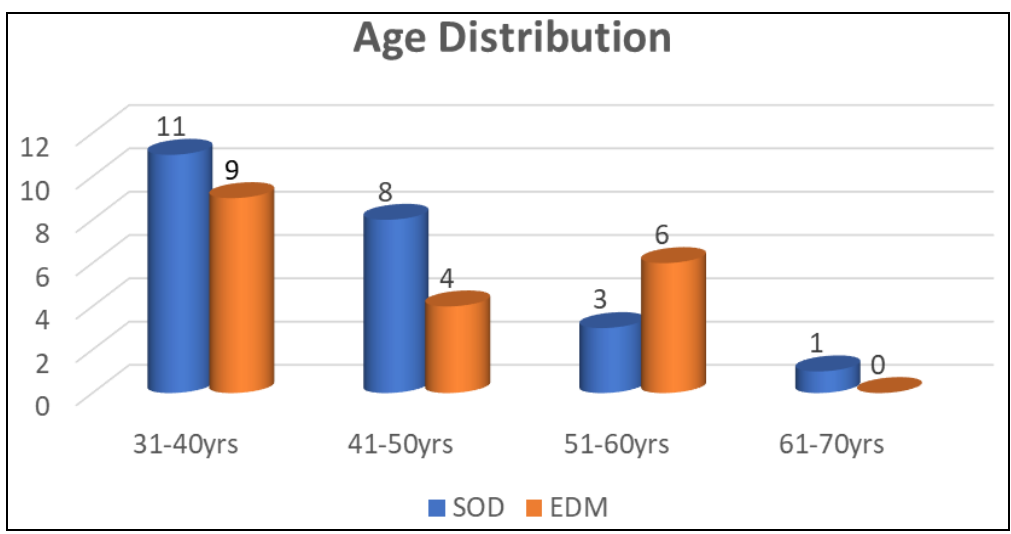

Fig 7: Case Distribution

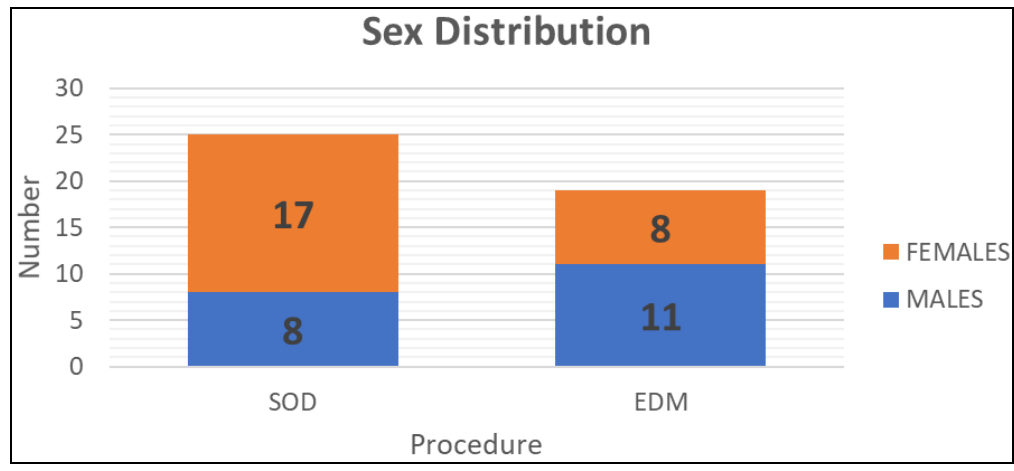

Fig 7: Sex Distribution

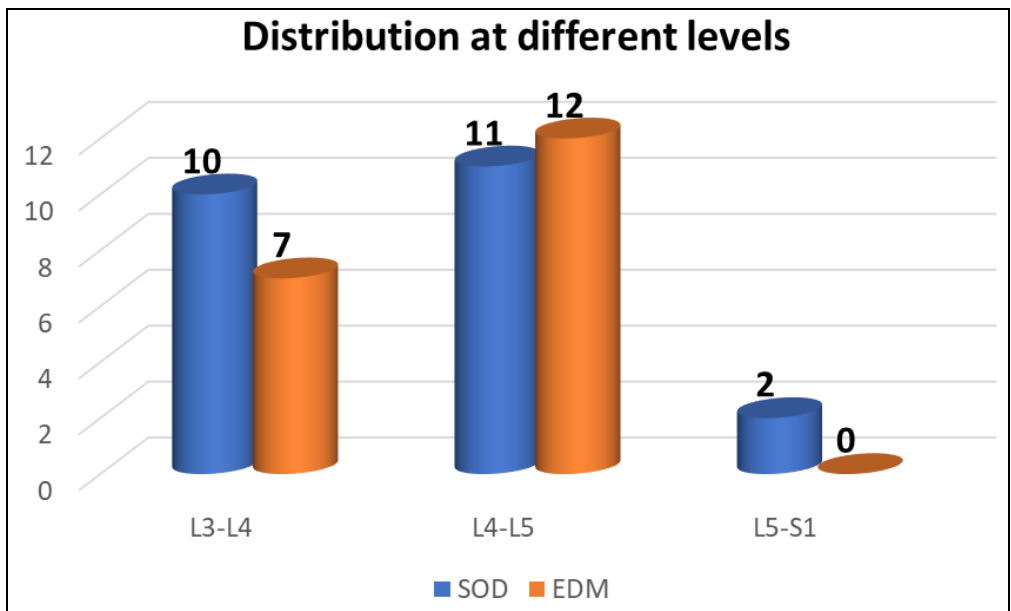


Fig 8: Distribution at different levels.

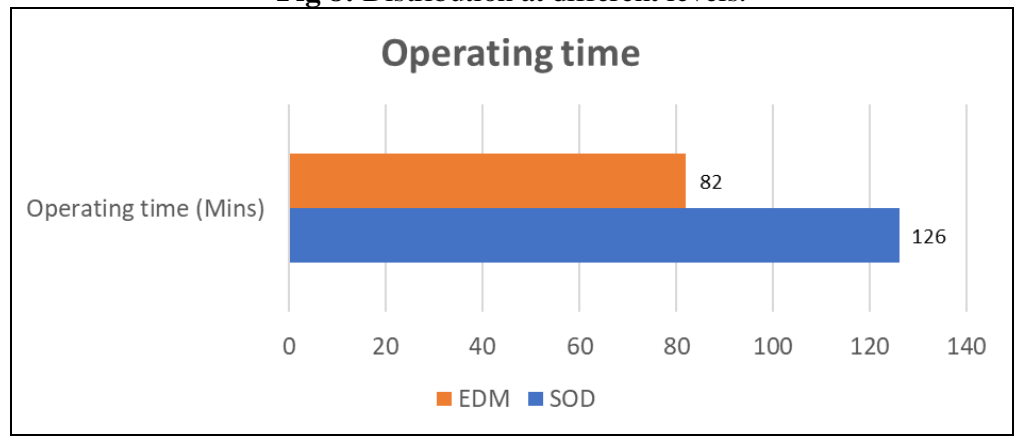

Fig 9: Operating time

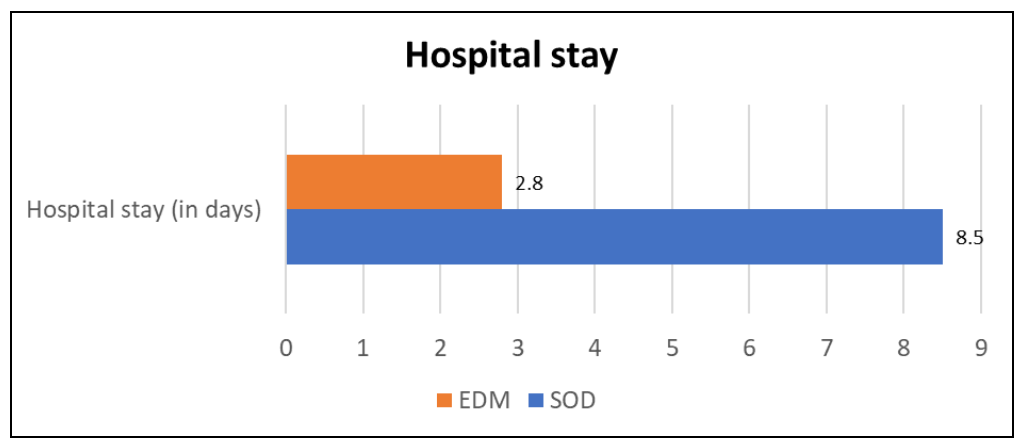

Fig 10: Hospital stay

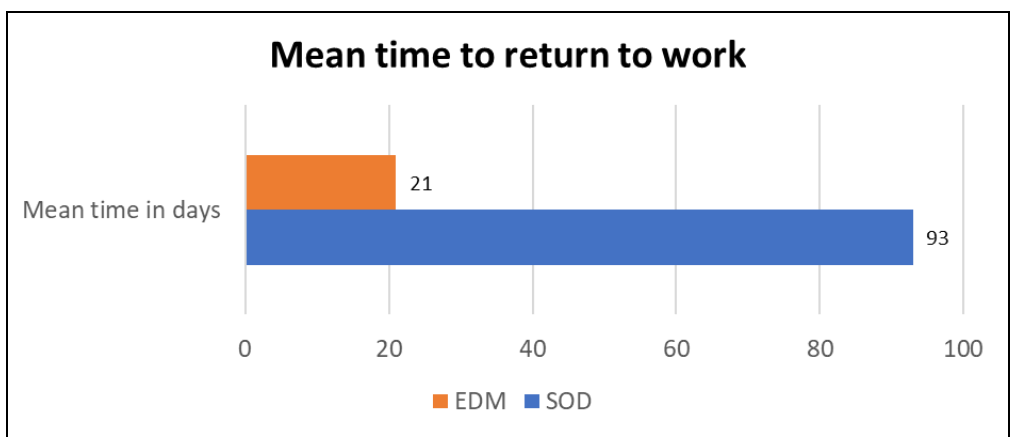

Fig 11: Mean time taken to return to work

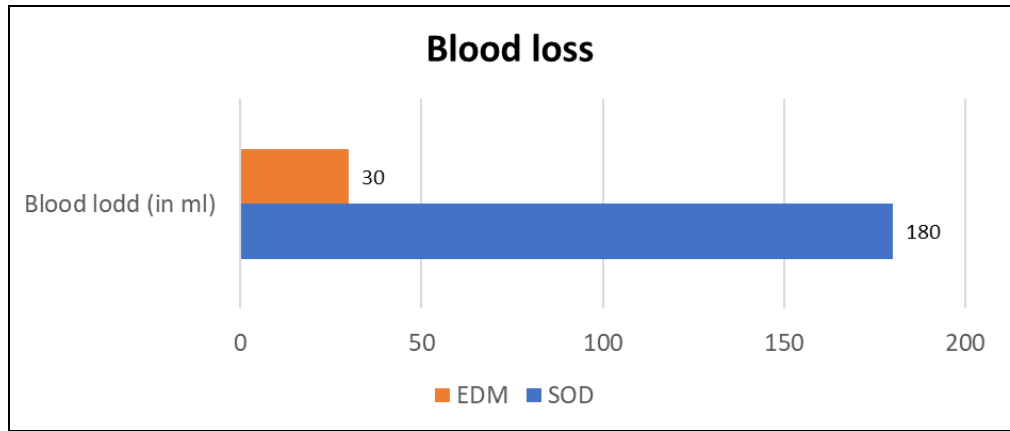

Fig 12: Blood loss

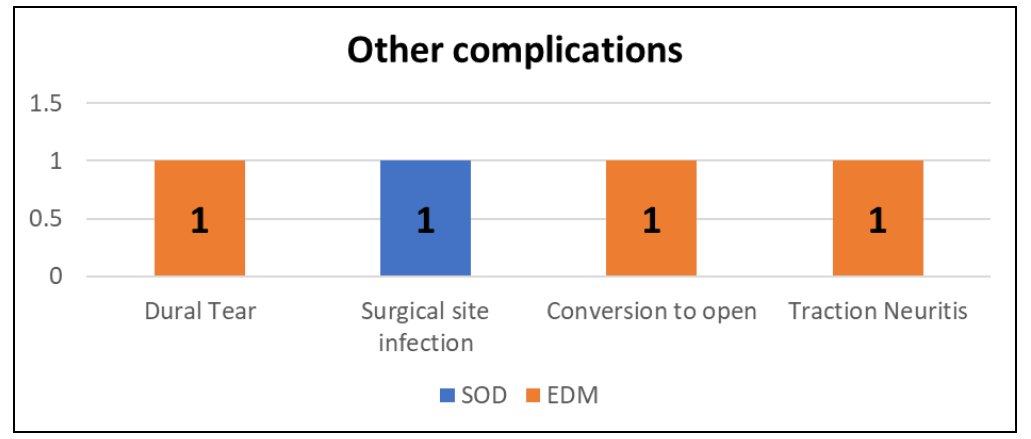

Fig 13: Other complications

$\sim 669 \sim$ 


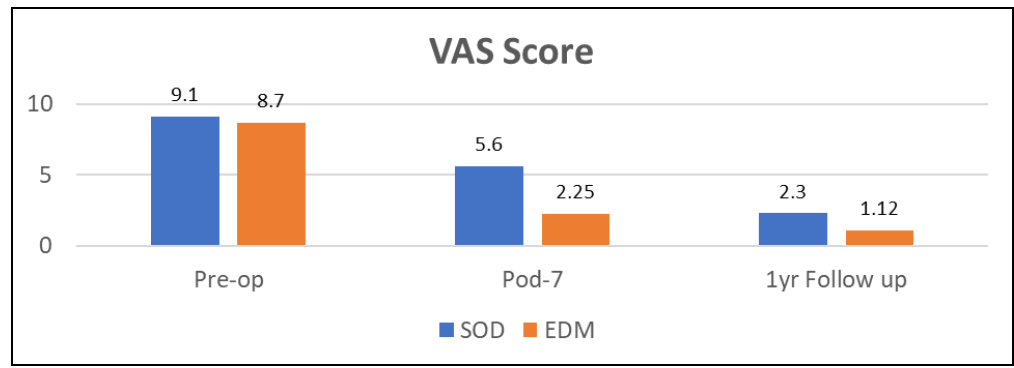

Fig 14: comparison of VAS score in SOD and EDM groups

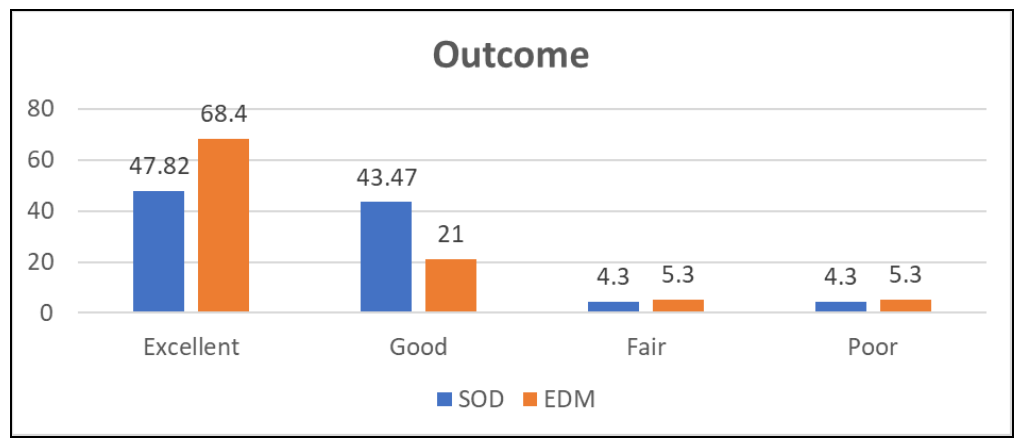

Fig 15: Outcome as per Macnab criteria

\section{Discussion}

Mixter and Barr ${ }^{[7]}$ are the first to suggest laminectomy and discectomy as a treatment to ivdp. 68-95\% success was reported in various studies ${ }^{[8]}$. The development of operative microscope and various microsurgical techniques by Yasargil and Krayenbuhl ${ }^{[9]}$ had redefined spinal surgery. Introduction of this microscope had resulted better outcome in the terms of smaller incisions, less blood loss, increased visualization, decreased hospitalization, shorter postoperative recovery, and earlier return to activities. Microdiscectomy which was considered as gold standar for lumbar disc prolapse surgery had a success rate of 85 to $98 \% .{ }^{[10]}$ Katayama et al. compared the results of open vs gold standard microdiscectomy and observed no difference between the surgical outcomes in both the groups but microdiscectomy group had better visualization of the pathological site and magnification which have resulted in reduced tissue trauma due to dissection, and smaller size of inscions ${ }^{[11]}$.

In 1993 Jean Destandau from France (with ENDOSPINE Karl Storz system) performed the endoscopic discectomy by the posterior approach. since then the same surgery was done in more than 10000 patients and results were encouraging. we have performed the same surgery in 19 patients and compared our results with 4 other studies. Destandau et al. $1999{ }^{\text {[5], }}$ Destandau et al. $2004^{[6]}$, Bhandari et al. $2006^{[12]}$, Roshan et al. $2016^{[13]}$.

In the present study, L4-L5 disc was most common location of disc herniation seen in $40.04 \%$ patients, L4-L5 in roshan et al. was (34.6\%). 37 patients $(37 \%)$ in Destandau 1999 study and 9 patients (42.85\%) in Bhandari 2006 study. L5-S1 disc herniation was seen in $(10.5 \%)$ in our study. In roshan et al. study L5-S1 disc was more commonly involved as in 11 patients $(52.38 \%)$ similar to Destandau 1999 series of 63 patients $(63 \%)$ and Bhandari 2006 series of 10 patients (38.6\%). The most frequent intraoperative complication was dural tear, as in present study it occurred in 1 patient $(5.2 \%)$. In Destandau 1999 series, dural tear occurred in 3 patients (3\%), in Destandau 2004 series in 2 patients $(0.69 \%)$, in Bhandari 2006 series in 2 patients $(7.66 \%)$ and roshan et al. in 1 patient $(4.76 \%)$. In the present study, conversion to open surgery was needed for 1 patient (5.2\%), in Destandau 2004 study it was needed in 2 patients $(1.39 \%)$, and in Bhandari 2006 study needed in 1 patient $(3.84 \%)$ and in 1 patient in roshan et al. (4.76\%). Superficial infection occurred in 1 patient $(5.2 \%)$ in the present study and in 1 patient $(3.84 \%)$ in Bhandari 2006 study and 1 patient in roshan et al. study. In this study $68.4 \%, 21 \%, 5.3 \%, 5.3 \%$ had excellent, good, fair and poor outcomes. In the study by Roshan et al., the results were excellent in 17 patients $(80.95 \%)$, good in 3 patients $(14.28 \%)$ and fair in 1 patient $(4.78 \%)$ and no patients with poor results. Destandau 1999 series had the following results, excellent in 78 patients $(85.71 \%)$, good in 9 patients $(9.89 \%)$, none with fair results, and poor in 4 patients $(4.39 \%)$. The results of Destandau 2004 series were excellent in 130 patients $(90.27 \%)$, good in 1 patient $(0.69 \%)$, poor in 13 patients $(9.02 \%)$, and none with fair result.

Table 1: comparison of various complications in different studies.

\begin{tabular}{|c|c|c|c|c|}
\hline Contents & Destandau et al. 2004 & Bhandari et al. 2006 & Roshan et al. 2016 & Present study \\
\hline Endoscopy sample size & 191 & 26 & 21 & 19 \\
\hline Dural tear & 1 & 1 & 1 & 1 \\
\hline Wound infection & 4 & 1 & 1 & 1 \\
\hline Conversion to open & 0 & 0 & 1 & 1 \\
\hline Temporary Neuro-deficit & - & - & 1 & 1 \\
\hline
\end{tabular}


procedure for surgical treatment of lumbar disk herniation in a semi-urban setup. This technique allows speedy recovery, lesser muscle dissection, faster discharge and early return to work. The outcome of the surgery is comparable to standard open discectomy.

\section{References}

1. Andersson GB. Epidemiological features of chronic lowback pain. Lancet. 1999; 354(9178):581-585.

doi: 10.1016/S0140-6736(99)01312-4.

2. Carette S, Leclaire $\mathrm{R}$, Marcoux $\mathrm{S}$, et al. Epidural corticosteroid injections for sciatica due to herniated nucleus pulposus. N Engl J Med. 1997; 336:1634-1640.

3. Weber H, Holme I, Amlie E. The natural course of acute sciatica with nerve root symptoms in a double-blind placebo-controlled trial evaluating the effect of piroxicam. Spine (Phila Pa 1976). 1993; 18:1433-8.

4. Amin RM, Andrade NS, Neuman BJ. Lumbar Disc Herniation. Curr Rev Musculoskelet Med. 2017; 10(4):507-516. doi:10.1007/s12178-017-9441-4

5. Destandau J. A special device for endoscopic surgery of lumbar disc herniation. Neurol Res. 1999; 21:39-42.

6. Destandau J. Technical features of endoscopic surgery for lumbar disc herniation: 191 patients. Neurochirurgie. 2004; 50:6-10.

7. Mixter WJ, Barr JS. Rupture of the intervertebral disc with involvement of spinal canal. N Engl J Med. 1934; 211:210-5.

8. Yorimitsu E, Chiba K, Toyama Y, Hirabayashi K. Long term outcomes of standard discectomy for lumbar disc herniation: A follow up study of more than 10 years. Spine (Phila Pa 1976). 2001; 26:652-7.

9. Yasagril MG, Krayenbuhl $\mathrm{H}$. The use of binocular microscope in Neurosurgery. Bibl Ophthalmol. 1970; 81:62-5.

10. Findlay GF, Hall BI, Musa BS, Oliveira MD, Fear SC. A10 year follow up of the outcome of lumbar microdiscectomy. Spine. 1998; 23:1168-71.

11. Katayama Y, Matsuyama Y, Yoshihara H, Sakai Y, Nakamura H, Nakashima S et al. Comparison of surgical outcomes between macro discectomy and microdiscectomy for lumbar disc herniation. A prospective randomized study with surgery performed by same surgeon. J Spinal Disord Tech. 2006; 19:344-7.

12. Bhandari S. Early experiences in endoscopic lumbar discectomy by destandau technique for prolapse intervertebral disc. J Maharashtra Orthop Assoc. 2006; 4:174-79.

13. Roshan B. Long-Term Results of Endoscopic Lumbar Discectomy by "Destandau's Technique "Asian Spine J. 2016; 10(2):289-297. 